Archived version from NCDOCKS Institutional Repository http://libres.uncg.edu/ir/asu/

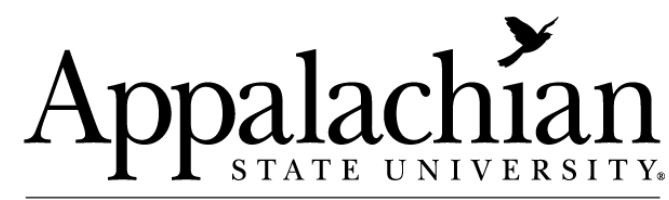

$\bar{B}$ O O N E, N O R T H A R O L N A

\section{Assisted Living Facility Administrator And Direct Care Staff Views Of Resident Mental Health Concerns And Staff Training Needs}

\author{
By: Emily Dakin, Louise M. Quijano, and Courtney McAlister
}

\begin{abstract}
This community needs assessment surveyed 21 administrators and 75 direct care staff at 9 larger and 12 smaller assisted living facilities (ALFs) regarding perceptions of resident mental health concerns, direct care staff capacity to work with residents with mental illness, and direct care staff training needs. Group differences in these perceptions were also examined. Both administrators and direct care staff indicated that direct care staff would benefit from mental health-related training, and direct care staff perceived themselves as being more comfortable working with residents with mental illness than administrators perceived them to be. Implications for gerontological social work are discussed.
\end{abstract}

Dakin, Emily, Quijano, Louise M. and McAlister, Courtney (2011). 'Assisted Living Facility Administrator and Direct Care Staff Views of Resident Mental Health Concerns and Staff Training Needs', Journal of Gerontological Social Work, 54: 1, 53-72. DOI: 10.1080/01634372.2010.530534. Publisher version of record available at: http://dx.doi.org/10.1080/01634372.2010.530534 


\title{
Assisted Living Facility Administrator and Direct Care Staff Views of Resident Mental Health Concerns and Staff Training Needs
}

\author{
EMILY DAKIN and LOUISE M. QUIJANO \\ School of Social Work, Colorado State University, Fort Collins, Colorado, USA \\ COURTNEY MCALISTER \\ Safe Shelter of St. Vrain Valley, Longmont, Colorado, USA
}

\begin{abstract}
This community needs assessment surveyed 21 administrators and 75 direct care staff at 9 larger and 12 smaller assisted living facilities (ALFs) regarding perceptions of resident mental bealth concerns, direct care staff capacity to work with residents with mental illness, and direct care staff training needs. Group differences in these perceptions were also examined. Both administrators and directcare staff indicated that direct care staff would benefit from mental bealth-related training, and direct care staff perceived themselves as being more comfortable working with residents with mental illness than administrators perceived them to be. Implications for gerontological social work are discussed.
\end{abstract}

KEYWORDS mental bealth, mental illness, long-term care, quantitative

Assisted living facilities (ALFs) are a critical service for older adults who wish to remain living in the community but can no longer do so independently. The Assisted Living Federation of America (ALFA), founded in 1991, defines assisted living as "a long-term care option that combines housing, support 
services and health care, as needed" (ALFA, n.d., para.1). The development of ALFs within the UnitedStates is influenced by the European emphasis on noninstitutional housing options for older adults, and in actuality, ALFs represent a middle ground that, at times, can become blurred between congregate housing and skilled nursing care (Spitzer, Neuman, \& Holden, 2004). They typically provide amenities such as housing; meals; housekeeping and laundry; security; and social, recreational, and wellness programs in a homelike environment. In addition, ALFs offer assistance with activities of daily living, medication management, access to health and medical appointments, emergency call systems, and care for persons with cognitive impairments (ALFA, n.d.).

Assisted living is defined by its unique philosophy, which emphasizes a social and resident-centered model of care, and a movement away fromtraditional, medically-oriented models of care (Utz, 2003). Social models of care emphasize holistic and individualized services as well asresidentcentered approachesthat promote autonomy and independence (Utz, 2003), thus allowing "greater resident control of his or her environment, including what services are received, when, and how" (Chapin \& Dobbs-Kepper, 2001, p. 43). In contrast, medical models dictate the patient's care based on an institutional schedule (Chapin \& Dobbs-Kepper, 2001). Despite a shared underlying philosophy, ALFs vary tremendously based on differing regulatory standards across states and a variety of facility-level characteristics (e.g., type of assisted living, size, commercial status, cost, and functional status of residents; Utz, 2003).

Over the last 25 years, ALFs have become an important alternative to nursing homes (Chapin \& Dobbs-Kepper, 2001; Wilson, 2007). Applebaum, Mehdizadeh, and Straker (2004) tracked growth in assisted living and in-home services and concurrent reductions in nursing home care over an 8year period in Ohio. An important reason for the growth in ALFs stems from shifting Medicaid expenditures away from nursing homes and into homeand-community-based services. Although the majority of ALF residents are on a private pay basis, 41 states offer Medicaid Home and Community-Based Services Waivers that allow low-income individuals to reside in ALFs (AFLA, n.d.; Carlson, Coffey, Fecondo, \& Newcomer, 2010). Waiver programs serve individuals who are eligible for nursing home care, so the term waiver is in specific reference to a nonnursing home long-term care option (Carlson et al., 2010).

Psychiatric deinstitutionalization in the 1960's led to movement toward community-based care settings, and it is now common for persons with severe mental illness, such as schizophrenia, to reside in public ALFs (Cadena, 2006). Furthermore, the traditional ALF population of frail eldersis, itself, vulnerable to mental illness. For example, estimates of depression rates among ALF residents range from 13\% to 24\% (Chapin \& Dobbs, 2004; Watson \& Lyketsos, 2006; Watson \& Zimmerman, 2003), and Rosenblatt 
et al. (2004) found that 26.3\% of traditional ALF residents have a current psychiatric disorder, inclusive of mood, anxiety, and psychotic disorders. In comparison, rates of depression among community-dwelling elders are estimated at $4.4 \%$ for women and $2.6 \%$ for men (Grayson, Lubin, \& Van Whitlock, 1995; Steffens et al., 2000). From a broader perspective, research (Gruber-Baldini, Boustani, Sloane, \& Zimmerman, 2004) has found that $34 \%$ of ALF residents exhibit one or more behavioral symptoms associated with dementia or psychiatric illness each week, and that two-thirds have some indicator of a mental health problem (e.g., dementia, depression, psychosis). Other research (Schonfeld, 2003) finds that ALFs are similar to nursing homes with respect to resident behavior problems associated with psychiatric illness or dementia. Perhaps equally significantare the rates of recognition and treatment of psychiatric illness in ALFs, which have been found to be quite low (Chapin \& Dobbs, 2004; Cummings \& Hayes, 2004; Rosenblatt et al., 2004; Watson \& Lyketsos, 2006; Watson \& Zimmerman, 2003). Research indicates that long-term care recipients with depression are themselves frustrated with their professional caregivers' limited ability to recognize and communicate about depression (Miller \& Kuruvilla, 2008).

There is a dearth of literature related to staff training needs in ALFs in comparison to the literature that exists related to nursing homes, which is especially problematic given that ALF regulations do not typically require the levels of professional staffing (e.g., nursing, social work, medical) that nursing homes do. Specifically, there is a lack of literature related to training needs for staff caring for residents with mental illness, whichis a huge concern, given the high rates of psychiatric disturbance within ALFs, and estimates that severe and persistent mental illness among residents will be a growing challenge in ALFs (Bartels, 2001).

\section{CONTEXT OF THE NEEDS ASSESSMENT}

In 1994, Colorado enacted a Medicaid Mental Illness Waiver (MI Waiver) as one of its Medicaid Home and Community-Based Services Waivers, thereby enabling ALFs to receive Medicaid reimbursement for residents with certain mental illnesses as a primary diagnosis. Populations served through the MI Waiver are frequently younger adults with severe mental illness. In passing the Medicaid MI Waiver, the state of Colorado ruled that individuals with a disabling mental illness who cannot live independently can access community housing that provides supervision and assistance with medication in a less restrictive environment; the only previous Medicaid option for these individuals was housing in nursing homes or psychiatric institutions. The creation of the MI Waiver led to the challenging circumstance of frail elders cohabitating with younger adults with severe 
mental illness, cared for by staff who were not trained to intervene when problems arose.

Prior to this study, the only knowledge about the impact of the MI Waiver on Colorado ALFs has been anecdotal in nature. Missing were data concerning percentage of residents residing in ALFs through the MI Waiver, the specific types of mental health and behavioral concerns present among residents in ALFs, and the extent to which direct care staff are perceived to be supported and comfortable working with residents with mental illness. Information was needed about mental health-related training that direct care staff had received, and that ALFs had provided. Also needed were data about the extent to which mental health training was perceived to be of potential benefit, as well asdesired topics for training. This valuable information can help to assess the capacity of ALFs to assume a role in caring for persons with mental illness in response to growing demand due to national trends and, in Colorado, the impact of the MI Waiver.

In response to these gaps in knowledge, we collaborated with staff at the Long-Term Care Ombudsman (LTC Ombudsman) Office within the county Area Agency on Aging to conduct a needs assessment, the primary audience of which consisted of a local community coalition that was formed to assess and address resident mental health issues within county ALFs. This coalition included representatives from the county Area Agency on Aging and its LTC Ombudsman program, the county program that assesses eligibility for Medicaid Waiver programs, university social work professors, the county mental health agency, and administrators from county ALFs. Secondarily, interest in the needs assessment and its results had been expressed by representatives from a statewide ALF professional organization and by people involved in policy related to human services and Medicaid Waiver programs at the state level. This needs assessment was guided by three aims discussed in the following.

\section{Needs Assessment Aim One}

The first aim of the needs assessment was to gather descriptive data about ALF facilities, staff, and residents relevant to resident mental illness and the MI Waiver. The descriptive data sought included percentages of residents residing in ALFs through the MI Waiver and perceived percentages of residents with mental illness, as well as mental health-related training that direct care staff had received and that ALFs had provided.

\section{Needs Assessment Aim Two}

A second aim was to determine ALF staff perceptions of resident mental health concerns, direct care staff capacity to work with residents with mental 
illness, and direct care staff training needs. These aims are addressed through the following research questions:

1. What do administrators and direct care staff identify as the resident mental health and behavioral concerns that are challenging to direct care staff?

2. To what extent do administrators and direct care staff perceive direct care staff to be supported in managing difficult resident behaviors?

3. To what extent do administrators and direct care staff perceive direct care staff to be comfortable in working with residents with mental illness?

4. To what extent do administrators and direct care staff perceive that mental health-related training would be beneficial for direct care staff?

5. What do administrators and direct care staff identify as potentially beneficial mental health-related topics for direct care staff training?

\section{Needs Assessment Aim Three}

The third aim was to assess group differences based on type of facility (larger, corporate-type facilities vs. smaller, family-run facilities) and type of staff (administrator vs. direct care), as well as interaction effects (facility by staff) with respect to the questions posed in Aim Two. In Colorado, ALFs are comprised of larger, corporate-type facilities and smaller businesses owned by individuals or families, the latter being formerly known by the term board-and-care facility. States vary in whether board-and-care facilities are included under assisted living regulations; we believed that it would be important to determine whether there were any differences between these two types of facilities (Carder, Morgan, \& Eckert, 2006). Similarly, in our desire to survey ALF staff, we believed that it would be important to examine any group differences between administrators and direct care staff. Analyses of group differences would include analyses of interaction effects. We did not have any specific assumptions or hypotheses concerning group differences or interaction effects. These aims are addressed through the following research questions:

6. Do differences exist between smaller, family-run ALFs and larger, corporate-type facilities with respect to questions 1-5?

7. Do differences exist between administrators and direct care staff with respect to questions $1-5$ ?

8. Do interactions effects exist based on type of facility and type of staff with respect to questions $1-5$ ?

This article provides the results of the needs assessment, discusses the relevance of the findings, and describes implications for gerontological social work. 


\section{METHODOLOGY}

Sample Selection and Procedure

The population for this study consisted of administrators and direct care staff from the 29 ALFs in the northern Colorado county where the needs assessment was conducted. The county is a nonmetropolitan area with mixed rural and urban characteristics and a population that is over 90\% Caucasian, with the remainder primarily Hispanic/Latino.

Completed needs assessment instruments were sought from one administrator and as many participating direct care staff within each facility as possible. The LTC Ombudsman provided investigators with a list of ALF facilities in the area, as well as names of their associated administrators. A coverletter was sent to all facility administrators describing the purpose of the needs assessment. This letter informed potential respondents that they would receive a follow-up phone call to determine their interest in completing the administrator needs assessment and inquired whether they would consider allowing their direct care staff to be interviewed as well.

In some cases, needs assessments were completed with administrators through telephone interviews with project staff. In other cases, needs assessments were sent to administrators via fax or e-mail to complete themselves; the majority of the administrators indicated a preference for this method of instrument completion. When an administrator was willing to have direct care staff members participate, a project staff person scheduled a time to come to the facility to enable one or more direct care staff to complete the needs assessment instrument. Although the direct care staff completed the instruments themselves in almost all cases, presence of project staff present allowed clarification of any questions. In a few cases, project staff played a more active role with participants with limited literacy by assisting with reading and completing the instrument.

\section{Needs Assessment Instruments}

Two needs assessment instruments were created, one for administrators and the other for direct care staff. (See Appendices A and B.) We developed the instruments following a review of the literature and in collaboration with staff at the Area Agency on Aging and LTC Ombudsman. After several revisions, we pilot-tested the instrument with four ALF administrators and several individuals who had previously worked as direct care staff. The instruments were then revised a final time based on the feedback received. The revisions were minor and primarily concerned wording of questions.

The administrator pilot instruments were retained and entered along with the rest of the administrator instruments. We believed that this variation from standard protocol was warranted due to the small population, concerns in community-based research such as the desire to not overburden 
administrators with a second survey request, and the minor nature of the revisions. The direct care staff pilot instruments were not entered, and the direct care staff members who were pilot tested were not surveyed later, because the pilot testing was done with people who had formerly worked as direct care staff but were not currently doing so. The administrator and direct care staff instruments consisted of 31 and 19 questions, respectively, with some areas of overlap on both instruments in addition to questions unique to each. Overlapping questions on the instruments were developed specifically for the purpose of analyzing potential differences between administrators and direct care staff. Identified differences between the groups would be used for tailoring the development of training modules by type of facility and staff. To promote greater readability and ease of completion, the administrator instrument was written at an 8th-grade reading level, and the direct care staff instrument was written at a 7th-grade reading level. The needs assessment instruments and proposed data collection procedures, including the informed consent process, received university IRB approval. The needs assessment instruments contained questions within the following domains:

Respondent and facility characteristics. Questions for administrators and direct care staff in this domain included demographic information, educational background, and current position within the facility. Administrators were also specifically asked to provide general facility census information.

Residents with mental illness and utilizing the MI Waiver. Administrators were asked to report the percentage ofresidents residing in their facility under the MI Waiver, and their general view as to the total percentage of their residents with mental illness. Administrators were also asked to report on percentages of residents with various types of mental illnesses under the MI Waiver and within the overall resident population.

Resident mental health and behavioral concerns. Administrators and direct care staff were asked to select items from a list of mental health and behavioral concerns that they considered challenging to their direct care staff.

Support received and comfort level. Questions within this domain asked, using a Likert-type scale from strongly no (1) to strongly yes (5), about the extent to which direct care staff and administrators believed that direct care staff receive adequate support to manage difficult resident behaviors. We also wished to know, using a Likert-type scale from not comfortable at all (1) to very comfortable (5), how comfortable administrators and direct care staff perceive direct care staff to bewhen working with residents with mental illness.

Prior mental health-related trainings provided and received. Administrators were asked to indicate whether their facility provides trainings for their staff related to resident mental illness, and if so, to indicate the topics and frequency with which trainings occur. We asked direct 
care staff to indicate any training related to mental health or challenging behaviors that they had received, and when and where they had received this training.

Perceived benefit, desired topics, and feasibility of future training. We next sought a variety of information from administrators and direct care staff concerning mental health-related training for direct care staff. We asked whether such training was perceived to be beneficial, using a Likert-type scale from strongly no (1) to strongly yes (5), and we asked administrators and direct care staffto select as many items from a list of possible training topics that they believed would be helpful to direct care staff. We also asked administrators, using a Likert-type scale from definitely not (1) through definitely could (5), whether it would be feasible for staff to take work time to attend training.

\section{Analysis}

The statistical data analysis program SPSS version 17 was used for running descriptive statistics. The statistical data analysis program SAS SAS/STAT software version 9.2 (SAS Institute, Cary, NC) was used to conduct analysis of variances comparing facility type (independent/family run vs. part of larger organization or company), position type (administrator vs. direct care), and interaction effects (facility type by position type) on the following: (a) a variable that was created as a summation of mental health and behavioral concerns; (b) extent to which direct care staff are perceived to be supported in managing difficult resident behaviors; (c) extent to which direct care staff are perceived to be comfortable in working with residents with mental illness; (d) perceived benefit of mental health-related training for direct care staff; (e) a variable that represented a summation of behavioral mental health training needs; and (f) a variable that represented a summation of knowledge mental health training needs.

To create the variable that represented a summation of mental health and behavioral concerns, we added all resident mental health and behavioral concerns (e.g., hallucinations or delusions, argumentativeness) that each respondent selected (e.g., if a respondent identified five challenging behaviors, their score would be five on the new summative variable) for a highest possible score of 21. Similarly, a variable that represented a summation of behavioral mental health training needs was created by adding the items (e.g., managing difficult behaviors, redirecting residents with mental health concerns) selected by each respondent for a highest possible score of nine. Another variable that represented a summation of knowledge mental health training needs was created by adding the items (e.g., telling the difference between dementia and mental illness, basic information about mental illness) selected by each respondent for a highest possible score of five. For effects that were significant $(p<.05)$, pair-wise comparisons were done 
TABLE 1 Cronbach's Alpha Scores for Summative Variables

\begin{tabular}{lcc}
\hline & \multicolumn{2}{c}{ Cronbach's alpha } \\
\cline { 2 - 3 } Variable & Administrators & Direct care staff \\
\hline Mental health and behavioral concerns (21 items) & 0.88 & 0.89 \\
Mental health behavioral training needs (9 items) & 0.81 & 0.87 \\
Mental health knowledge training needs (5 items) & 0.77 & 0.72 \\
\hline
\end{tabular}

with $t$-tests. Reliability was assessed for the three summative variables, and determined to be in acceptable ranges for all three variables (see Table 1).

\section{RESULTS}

\section{Respondent and Facility Characteristics}

Table 2 summarizes data on respondent characteristics. Administrators from 21 different facilities ( $72.41 \%$ of 29 possible facilities) agreed to participate in the needs assessment. Of these 21 facilities, 12 (57.14\%) were categorized as independent/family run and 9 (42.86\%) were categorized as part of a larger organization or company. A total of 75 direct care staff from 19 facilities (65.51\% of 29 possible facilities, and an average of 3.95 per facility) completed the needs assessment. A subsequent analysis indicated an average of 22.11 direct care (i.e., nonadministrative) staff per ALF at the

TABLE 2 Demographic Characteristics of Administrators and Direct Care Staff in Assisted Living Facilities

\begin{tabular}{|c|c|c|c|c|}
\hline \multirow[b]{2}{*}{ Characteristic } & \multicolumn{2}{|c|}{ Administrators } & \multicolumn{2}{|c|}{ Direct care staff } \\
\hline & $N$ & $\%$ & $N$ & $\%$ \\
\hline Age (Mean years) & 45.90 & & 35.91 & \\
\hline 17 or less & - & - & 2 & 2.86 \\
\hline $18-24$ & 1 & 5.00 & 14 & 20.00 \\
\hline $25-34$ & 5 & 25.00 & 23 & 32.86 \\
\hline $35-44$ & 1 & 5.00 & 12 & 17.14 \\
\hline $45-54$ & 8 & 40.00 & 11 & 15.71 \\
\hline 55 and above & 5 & 25.00 & 8 & 11.43 \\
\hline \multicolumn{5}{|l|}{ Gender } \\
\hline Male & 7 & 33.33 & 6 & 8.11 \\
\hline Female & 14 & 66.67 & 68 & 91.89 \\
\hline \multicolumn{5}{|l|}{ Ethnicity } \\
\hline Hispanic/Latino & - & - & 12 & 16.44 \\
\hline Caucasian & 20 & 95.24 & 54 & 73.97 \\
\hline African American & - & - & 2 & 2.74 \\
\hline Asian/Hawaiian/Pacific & - & - & 2 & 2.74 \\
\hline Multiracial & 1 & 4.76 & 3 & 4.11 \\
\hline Level of education (Mean years) & 15.75 & & 13.42 & \\
\hline
\end{tabular}


19 ALFs where direct care staff were surveyed. This indicates a response rate of $17.87 \%$.

Direct care staff reported carrying out a wide variety of positions in ALFs, including Qualified Medication Administration Person (69.33\%), direct care provider (46.67\%), laundry (34.67\%), housekeeping (29.33\%), dietary (28.00\%), activities (22.67\%), nursing (13.33\%), office staff (10.67\%), transportation (4.00\%), and building maintenance (4.00\%). Each direct care staff could indicate more than one job category, which was particularly relevant at smaller facilities where one person may be providing most of the above functions.

The mean years of formal schooling for direct care staff was 13.42 years (slightly more than a year beyond high school), with a range of 6 years to 17 years of formal schooling. Some direct care respondents had formal education extending beyond a bachelor's degree. Administrators years of formal schooling ranged from 12 years (completed high school or the equivalent) to 20 years (earned two master's degrees), with a mean of 15.75 years. Administrators listed their professional backgrounds as being business (52.38\%), nursing (23.81\%), and social work (14.29\%; one administrator had social work and business backgrounds). Three participants had either no response or a professional background in another discipline.

\section{Residents With Mental Illness and Utilizing the MI Waiver}

Administrators were asked to indicate the percentage of their residents with any mental illness, the percentage of their residents with specific mental illnesses, the percentage of their residents on the MI Waiver, and the percentage of their residents on the MI Waiver with specific mental illnesses. We were guided by the mental illness categories that are used to determine eligibility for the Colorado Medicaid MI Waiver. Table 3 provides a list of percentages of the total resident population and residents on the MI Waiver with various types of mental illness. Administrator responsesto the questions regarding the percentage of residents with mental illness were based on impression, rather than diagnoses, diagnostic criteria, or diagnostic instruments. However, administrator responses regarding MI Waiver data is factual, documented information that can be readily referenced in their resident population. Administrators reported a mean of $26.0 \%$ of residents with mental illness, with a range from $0 \%$ to $100 \%$ of the resident population. Administrators reported a mean of $12.69 \%$ of residents with major depressive disorder, with a range from $0 \%$ to $100 \%$, and $0 \%$ as the modal response. Additionally, administrators reported a mean of $6.40 \%$ of the resident population on the MI Waiver, with a range from $0 \%$ to $94.12 \%$, and $0 \%$ as the modal response. 
TABLE 3 Mean Percentage and Standard Deviation of Residents With Specific Mental Illnesses (MI)

\begin{tabular}{lrrrrrr}
\hline & \multicolumn{2}{c}{$\begin{array}{c}\text { Total resident } \\
\text { population }\end{array}$} & & & \multicolumn{2}{c}{$\begin{array}{c}\text { Residents on } \\
\text { the MI waiver }\end{array}$} \\
\cline { 2 - 3 } Mental illness & Mean & & $S D$ & & Mean & $S D$ \\
\hline Total & 26.02 & 35.36 & & 6.40 & 20.92 \\
Paranoia & 1.42 & 3.84 & & 1.54 & 5.39 \\
Bipolar disorders & 2.82 & 6.39 & & .78 & 2.76 \\
Major depressive disorder & 12.69 & 27.52 & & 1.35 & 3.41 \\
Dysthymia disorder & .10 & .44 & & .13 & .57 \\
Cyclothymiadisorder & .00 & .00 & & .00 & .00 \\
Schizoaffective disorder & 2.06 & 6.03 & & .84 & 3.84 \\
Psychosis disorder & 2.69 & 6.80 & & .37 & 1.32 \\
Generalized anxiety disorder & 7.63 & 10.65 & & - & - \\
Anxiety disorder not otherwise specified & 3.78 & 9.58 & & - & - \\
Obsessive compulsive disorder & .40 & 1.37 & & - & - \\
Panic disorder & 1.80 & 4.99 & & - & - \\
\hline
\end{tabular}

Note. Missing data refers to diagnoses not recognized on the MI Waiver. Administrator response to the percentage of residents within the total resident population with specific mental illnesses was based on their impression. The total score for total resident population reflects administrators response to the question, "What percentage of your total resident population have a mental illness?" The MI Waiver data, however, is documented information that administrators can readily reference in their resident population.

\section{Resident Mental Health and Behavioral Concerns}

Table 4 reflects the top 10 of 21 mental health and behavioral concerns identified by administrators and direct care staff. Overall, administrators and direct care staff shared nine of the top ten mental health and behavioral

TABLE 4 Mean Percentage and Standard Deviation of the Top 10 Mental Health or Behavioral Concerns of Administrators and Direct Care Staff

\begin{tabular}{|c|c|c|c|c|}
\hline \multirow[b]{2}{*}{ Mental illness or behavioral concerns } & \multicolumn{2}{|c|}{ Administrators } & \multicolumn{2}{|c|}{ Direct care staff } \\
\hline & Mean & $S D$ & Mean & $S D$ \\
\hline Hallucinations or delusions & 42.86 & 50.71 & 32.00 & 46.96 \\
\hline Unnecessary dependence on staff & 42.86 & 50.71 & 42.67 & 49.80 \\
\hline Manipulative behaviors & 61.90 & 49.76 & 37.33 & 48.69 \\
\hline Argumentativeness & 57.14 & 50.71 & 49.33 & 50.33 \\
\hline Sadness/being down in the dumps/blue & 33.33 & 48.30 & 38.67 & 49.03 \\
\hline Agitation & 52.38 & 51.18 & 38.67 & 49.03 \\
\hline Confusion or diminished intellectual skills & 47.62 & 51.18 & 41.33 & 49.57 \\
\hline Angry or violent outbursts & 42.86 & 50.71 & 46.67 & 50.22 \\
\hline Memory loss & 42.86 & 50.71 & 44.00 & 49.97 \\
\hline Being very withdrawn/apathetic & 42.86 & 50.71 & 34.67 & 47.91 \\
\hline Sudden changes in mood & 23.81 & 43.64 & 37.33 & 48.69 \\
\hline
\end{tabular}


concerns, and argumentativeness was among the top three concerns of both administrators and direct care staff.

\section{Support Received and Comfort Level}

Perceptions of support. Administrators were asked whether they believed their staff received adequate support to manage difficult resident behaviors when they occur. Their mean response was 3.76 out of 5 , indicating a score between neutral and yes. When asked whether they believed they were adequately supported in managing difficult resident behaviors, direct care staff reported a mean of 3.88 out of 5, slightly higher than the administrators' reported perceptions but also indicating a score between neutral and yes.

Perceptions of comfort. Administrators and direct care staff were asked to indicate how comfortable they perceived direct care staff to be in working with residents with mental illness. The mean for administrators was 3.33 out of 5 , indicating that they perceived direct care staff to be approximately neutral in working with residents with mental illness. The mean for direct care staff was higher at 4.13 out of 5 , indicating that they perceived themselves to be comfortable in working with residents with mental illness.

\section{Prior Mental Health Trainings Provided and Received}

Provision of mental health-related training. Of the 21 administrators who completed a needs assessment instrument, 13 or $61.90 \%$ indicated that their facility provides training for staff related to resident mental illness. The frequency of these trainings ranged from bimonthly to annually, without a most common frequency. Reported mental health-related training topics included general information on mental health/mental illness (4), dealing with/managing difficult behaviors (4), depression (2), bipolar disorder (1), personality disorders (1), and anxiety (1). However, of the nine administrators who listed specific mental health-related topics about which their facility had provided training, two included Alzheimer's and/or dementia in their response, suggesting that ALF administrators may not all understand the difference between dementia and mental illness.

Mental bealth-related training received by direct care staff. Direct care staff members were asked what, if any, specific training about the topic of mental health or challenging behaviors they had received, either at their current workplace or elsewhere. Thirty-four (45.33\%) of 75 respondents either did not respond to this question, or stated that they had not had training on this topic. Nine respondents referenced training topics related to Alzheimer's disease or dementia, suggesting a lack of understanding about the difference between dementia and mental health (although they may have 
been specifically referring to challenging behaviors, which also occur with dementia).

Additionally, direct care staff members were asked when and where they had received this training. Dates for most recently received mental health-related trainings ranged from 1976 to 2008 (the year the assessment took place). The modal year was 2008, with 10 (13.33\%) respondents indicating this year. Two-thirds of the respondents who had received mental health training did so within the last 5 years, with the remainder ranging from 1976 through 2002.

Nineteen (25.33\%) direct care staff members indicated that they had received mental health education through their employment at an assisted living facility, whereas eight (10.67\%) direct care staff said that they received mental health education in a college or university setting, in addition to or apart from their job. Seven (9.33\%) respondents indicated that they received training on mental health-related topics through other professional development avenues, such as Certified Nursing Assistant (CNA) training.

Perceived Benefit, Desired Topics, and Feasibility of Future Trainings

Perceived benefit of mental health-related training. Administrators and direct care staff were asked if they believed that direct care staff members at their facility could benefit from training about resident mental health concerns. The mean response of administrators and direct care staff were 4.10 and 3.91, respectively, both suggesting a general perception that mental health-related training would be beneficial.

Desired mental health-related training topics. The mental health training topic, inclusive of both behavioral and knowledge training needs, that was most desired by both administrators and direct care staff was managing difficult behaviors, at $80.95 \%$ and $58.67 \%$, respectively. See Table 5 for the mean percentages of the most frequently identified training topics among administrators and direct care staff.

Feasibility of future mental health-related trainings. Administrators were asked to indicate whether it would be feasible for staff to take work time to attend mental health-related training. The mean score was 3.76 out of 5, suggesting that administrators were somewhat supportive of staff taking work time to attend training.

\section{Group and Interaction Differences}

Analysis of variance showed a significant difference between administrators and direct care staff regarding perceived comfort level of direct care staff in working with residents with mental illness. Direct care staff members perceived themselves as more comfortable $(p<.01)$ in working with residents with mental illness than administrators perceived them to be. 
TABLE 5 Mean Percentage and Standard Deviation of the Top 10 Behavioral and Knowledge Mental Health Training Needs Identified by Administrators and Direct Care Staff

\begin{tabular}{|c|c|c|c|c|}
\hline \multirow[b]{2}{*}{ Training needs } & \multicolumn{2}{|c|}{ Administrators } & \multicolumn{2}{|c|}{ Direct care staff } \\
\hline & Mean & $S D$ & Mean & $S D$ \\
\hline Managing difficult behaviors & 80.95 & 40.24 & 58.67 & 49.57 \\
\hline $\begin{array}{l}\text { Redirecting residents with mental health } \\
\text { concerns }\end{array}$ & 76.19 & 43.64 & 40.00 & 49.32 \\
\hline $\begin{array}{l}\text { Dealing with conflicts between residents } \\
\text { with mental health issues }\end{array}$ & 61.90 & 49.76 & 57.33 & 49.79 \\
\hline Dealing with threatening behaviors & 38.10 & 49.76 & 52.00 & 50.30 \\
\hline Medication management or noncompliance & 19.05 & 40.24 & 25.33 & 43.78 \\
\hline Wandering and elopement & 23.81 & 43.64 & 29.33 & 45.84 \\
\hline Hallucinations and delusions & 42.86 & 50.71 & 32.00 & 46.96 \\
\hline Suicide & 9.52 & 30.08 & 34.67 & 47.91 \\
\hline Sexuality & 33.33 & 48.30 & 26.67 & 44.52 \\
\hline Basic information about mental illness & 42.86 & 50.71 & 34.67 & 47.91 \\
\hline $\begin{array}{l}\text { Telling the difference between dementia } \\
\text { and mental illness }\end{array}$ & 61.90 & 49.76 & 56.00 & 49.97 \\
\hline Bereavement and grief & 38.10 & 49.76 & 26.67 & 44.52 \\
\hline $\begin{array}{l}\text { Normal aging/understanding the aging } \\
\text { process }\end{array}$ & 57.14 & 50.71 & 29.33 & 45.84 \\
\hline
\end{tabular}

There were no significant differences between groups by type of facility, type of staff, or the interaction of facility type by position type among the other compared variables: summative mental health and behavioral concerns variable, perceived support of direct care staff in managing difficult resident behaviors, perceived benefit of mental health-related training for direct care staff, or summative behavioral mental health training needs or knowledge mental health training needs variables. Residuals from the analysis of variance were examined. The residuals appeared normally distributed and independent.

\section{DISCUSSION}

Both administrators and direct care staff perceived the benefit of mental health training for direct care staff, and administrators further indicated that they would likely allow direct care staff to take work time to receive training. Furthermore, this study found broad general agreement among both administrators and direct care staff regarding the specific behaviors that are problematic and the areas of training that are desired, with both topic areas focusing on management of difficult (e.g., manipulative, argumentative, aggressive, angry, withdrawn, confused or dependent) behavior, and understanding the difference between dementia and mental illness. 
Administrators reported a mean of $26.02 \%$ of residents with mental illness, which is extremely close to Rosenblatt et al.'s (2004) finding that $26.3 \%$ of traditional assisted living residents have a current psychiatric disorder, inclusive of mood, anxiety and psychotic disorders. Similarly, the mean administrator estimate for major depressive disorder was 12.69, which is also consistent with estimates of depression rates among assisted living facility residents ranging from $13 \%$ to $24 \%$ (Chapin \& Dobbs, 2004; Watson \& Lyketsos, 2006; Watson \& Zimmerman, 2003). It is important to note, however, that administrators' perceived percentage of residents with mental illness ranged from $0 \%$ to $100 \%$. Administrators' perceived percentage of residents with depression also ranged from $0 \%$ to 100\%, with $0 \%$ being the modal response. These findings suggest a range of sensitivity to and awareness of mental health concerns among our sample of ALF administrators, or perhaps different understandings of what was meant by the term mental illness.

Both administrators and direct care staff tended to confuse mental illness and dementia. Although administrators report providing training about mental illness to direct care staff, the direct care staff surveyed reported very limited training histories related to mental health or challenging behaviors. This discrepancy could be due to staff turnover, suggesting the need for regular mental health training. When direct care staff did indicate prior trainings related to mental health or challenging behaviors, they frequently reported topics related to Alzheimer's disease or dementia. This suggested either that previous training had focused on challenging behaviors related to dementia rather than mental illness, or perhaps a limited understanding of the difference between dementia and mental illness. Of the nine administrators who listed specific mental health-related topics about which their facility had provided training, two included Alzheimer's and/or dementia in their response. This suggests that facility administrators, themselves, may not understand that mental illness and dementia are separate topics. Consistent with the apparent limited understanding of the difference between mental illness and dementia, the training topic "telling the difference between dementia and mental illness" was also one of the top four desired training topics among both administrators and direct care staff.

Direct care staff perceived themselves as more comfortable in working with residents with mental illness than administrators perceived them as being. Among the participants in this study, administrators had backgrounds largely in business, rather than human services, and direct care staff members, overall, had limited formal education or on-the-job training related to mental health; thus, participants in this study may have been more confident than prepared to address the needs of residents with mental illness. Although the perceived level of comfort could be promising, this study did not focus on actual skills, competencies, and knowledge of direct care staff in working with adults diagnosed with a severe mental illness. 


\section{Implications for Gerontological Social Work}

The ALF is often a preferred long-term care option for elders who are no longer able to remain living independently at home. There is an important role for social workers in ALFs, particularly based on the ALF philosophy of a social and holistic model of care, which is very consistent with social work's biopsychosocial approach and with the emphasis that the profession places on the importance of human relationships. The ALF philosophy around client-centered care is also consistent with social work's emphasis on client dignity, empowerment, and self-determination (Feinberg, 2002; National Association of Social Workers, n.d.-a; Williams, 2002). Social workers are trained to look at clients from a wider lens by considering systems issues, including mezzo influences such as the family and macro influences such as community and societal systems. They are also trained to be sensitive to issues related to autonomy, privacy, and resident rights that are significant in the ALF environment (Feinberg, 2002; Williams, 2002). A number of basic social work skills are invaluable in ALF settings, including mediation, listening, resident and family psychoeducation, assessment, group work, planning interventions, advocacy, and resource coordination (Spitzer et al., 2004; Vinton, 2004; Williams, 2002). Furthermore, clinical social workers are skilled with identifying and treating mental health concerns (e.g., depression and anxiety) that so often go undiagnosed within ALFs, crisis intervention, end of life care planning, and with engaging the whole family system with psychotherapeutic interventions (Feinberg, 2002; Spitzer et al., 2004). Vinton found that ALFs that employ social workers are significantly more likely than those that do not to "offer bereavement, crisis, family, and substance abuse counseling" (p. 85). However, in addition to the clinician role, social workers can play many other valuable roles within ALFs such as in administration, community relations and marketing, program evaluation and research, and policy advocacy (Feinberg, 2002; Spitzer et al., 2004). Feinberg (2002) argued additionally that, although many social workers gravitate toward nonprofit ALFs due to their mission, which appears consistent with social work values, there is also a great value in bringing social work values and perspectives to work within for-profit ALFs.

Unlike skilled nursing facilities, state licensing regulations typically do not require ALFs to employ social workers and, indeed, Vinton (2004) found that only 17 of a sample of 140 Florida ALFs did. An important area for social work advocacy is around the value and role of social workers in ALFs. Additionally, because social workers are often not employed within ALFs, LTC Ombudsman programs become particularly important in monitoring these facilities and providing oversight, advocating for residents' rights, and resolving complaints made by or on behalf of residents (National LTC Ombudsman Resource Center, 2009; U.S. Department of Health and Human Services, 2009). LTC Ombudsman programs utilize a social work perspective given their emphasis on advocacy, meeting the residents where 
they are and proceeding at a pace appropriate for them, a multisystem focus (micro-resident to macro-community), provision of mediation and conflict resolution services, and a focus on maximizing resident quality of life, independence, and empowerment (Arcus, 1999). Consequently, LTC Ombudsmen programs often hire BSW or MSW-level social workers as professional ombudsmen. In addition to the social work role provided by the LTC Ombudsman, social workers in community mental health or private clinical practices may also interface with ALF residents by providing case management and psychotherapy.

\section{Next Steps}

Results of this study indicate that ALF administrators and direct care staff could both benefit from training on resident mental health. Training administrators, using a train-the-trainer model, with subsequent direct care staff training from administrators, would be beneficial in several ways. First, there is frequent turnover among direct care staff in ALFs, suggesting that the training an employee may have received on-the-job potentially leaves the facility upon his or her departure. Through communication with our collaborating LTC Ombudsman, we have come to understand that there is generally less turnover among administrators, and consequently, an effort to train both administrators and direct care staff using a train-the-trainer model with administrator trainers is more likely to be sustained over time. Second, if the administrators are trained, they can offer ongoing education and assistance to direct care workers as the need arises, which ultimately benefits the facility and protects the residents. Third, if administrators are educated and trained, direct care staff may perceive that administrators have listened to their concerns about resident care and are interested in resolving issues with them, potentially resulting in a boost in morale.

Given the valuable role of social workers within assisted living facilities and the fact that social workers provide the majority of community mental health services in the United States (National Association of Social Workers, n.d.-b), the social work profession has a uniquely important role to play in developing and providing training concerning the management of resident mental illness within ALFs. An important area for macro-level social work intervention is to establish coalitions representing community mental health, LTC Ombudsman Programs, Medicaid Home and Community-Based Services eligibility programs, clinical gerontological social workers, and assisted living facility staff to address mental health concerns within ALFs through training interventions or targeted mental health inventions that ALFs themselves are not able to provide. All educational modules would benefit from an evaluation component thatexamines participants' knowledge and skill development as a result of training. 
If ALF staff in Colorado could be trained to work more effectively with residents residing within ALFs through the MI Waiver, perhaps more ALF administrators would be willing to accept MI Waiver residents. The development of successful training approaches could also encourage other states to adopt MI Waivers, thereby expanding non-institutional care options for persons with severe mental illness. Indeed, residing within an ALF may be beneficial for persons with severe mental illness; research by Gilmer et al. (2003) found that residence within an ALF resulted in greater use of outpatient mental health services and lower rates of psychiatric and medical care hospitalizations among persons with schizophrenia, in comparison with persons with schizophrenia who were living independently or were homeless.

\section{Limitations}

One of the limitations of this study was the small sample size, which made significant group differences difficult to detect. A larger sample would have been challenging to obtain in this case, as only 29 assisted living facilities were located within the county.

Data regarding resident mental health concerns were drawn from administrator self-report, which is noteworthy because administrators generally did not have strong backgrounds in mental health. However, we were instead interested in assessing administrator perceptions of the extent of resident mental illness, to help examine how aware administrators actually are about the extent of mental illness within their facilities. Administrator estimates ranged from $0 \%$ to $100 \%$ for both percentage of residents with mental illness and percentage of residents with depression, with $0 \%$ being the modal response for depression, which suggests a range of sensitivity to and awareness of mental health concerns among our sample of ALF administrators. Furthermore, because other data sources were not available (due to the general lack of state or county-level information on utilization and impact of the Medicaid MI Waiver on ALFs), administrator self-report represented the best available data source for this study.

A limitation can be observed in Table 3. Administrators were asked to indicate the percentage of the total resident population with specific mental illnesses. These percentages were intended to be inclusive of residents on the MI Waiver. However, in certain cases (i.e., paranoia and dysthymia) there is a higher indicated percentage of residents on the MI Waiver than percentage of total resident population with these conditions. This indicates some lack of clarity in the question and/or error in the administrator response.

Finally, this needs assessment focused on the perceptions of ALF administrators and direct care staff. Residents were not consulted, which can be seen as a limitation of this project; resident perceptions around staff training needs is a valuable direction for future research. 


\section{Conclusion}

This needs assessment represents an important step toward understanding administrator and direct care staff views of resident mental health concerns and training needs in assisted living. The needs assessment indicates that both administrators and direct care staff value training around topics such as managing difficult behaviors, understanding the difference between dementia and mental illness, appropriately addressing conflicts between residents with mental health issues, and redirecting residents with mental health concerns. Ultimately, the most important outcome measure in ALFs is resident quality of life, whether or not the resident is a person who suffers from mental illness. Effective staff training in topics relevant to residents with mental illness is one important means of promoting a strong quality of life for all ALF residents.

\section{REFERENCES}

Applebaum, R. A., Mehdizadeh, S. A., \& Straker, J. K. (2004). The changing world of long-term care: A state perspective. Journal of Aging and Social Policy, 16, $1-19$.

Arcus, S. G. (1999). From the world of practice. The long-term care ombudsman program: A social work perspective. Journal of Gerontological Social Work. 31(1/2), 195-205.

Assisted Living Federation of America. (n.d.). What is assisted living? Retrieved, from http://www.alfa.org/alfa/Assisted_Living_Information.asp?SnID=1895298073

Bartels, S. (2001). Mental health: Assisted living's next challenge. Assisted Living Today, 8(5), 25-27.

Cadena, S. V. (2006). Living among strangers: The needs and functioning of persons with schizophrenia residing in an assisted living facility. Issues in Mental Health Nursing, 27, 25-41.

Carder, P. C., Morgan, L. A., \& Eckert, J. K. (2006). Small board-and-care homes in the age of assisted living. Generations, 29(4), 24-31.

Carlson, E., Coffey, G., Fecondo, J., \& Newcomer, R. (2010). Medicaid funding for assisted living care: A five-state examination. Journal of Housing for the Elderly, $24,5-27$.

Chapin, R., \& Dobbs-Kepper, D. (2001). Aging in place in assisted living: Philosophy versus policy. Gerontologist, 41, 43-50.

Chapin, R., \& Dobbs, D. (2004). Mental health needs and service use of older adults in assisted living settings: A mixed methods study. Journal of Mental Health and Aging, 10, 351-365.

Cummings, S., \& Hayes, J. (2004). Assisted living facilities' response to residents' mental health needs: A study in two states. Journal of Mental Health and Aging, 10, 151-162.

Feinberg, R. K. (2002). The increasing need for social workers in assisted living. Journal of Social Work in Long-Term Care, 1(3), 9-11.

Gilmer, T. P., Folsom, D. P., Hawthorne, W., Lindamer, L. A., Hough, R. L., Garcia, P., \& Jeste, D. V. (2003). Assisted living and use of health services among 
Medicaid beneficiaries with schizophrenia. Journal of Mental Health Policy and Economics, 6, 59-65.

Grayson, P., Lubin, B., \& Wan Whitlock, R. (1995). Comparison of depression in the community-dwelling and assisted-living elderly. Journal of Clinical Psychiatry, $15,18-21$.

Gruber-Baldini, A. L., Boustani, M., Sloane, P. D., \& Zimmerman, S. (2004). Behavioral symptoms in residential care/assisted living facilities: Prevalence, risk factors, and medication management. Journal of the American Geriatrics Society, 52, 1610-1617.

Miller, D., \& Kuruvilla, G. (2008). Personal carers' knowledge and response to depression among their aged-care clients: The care recipients' perspective. Aging and Mental Health, 12, 389-399.

National Association of Social Workers. (n.d.-a). Code of ethics. Retrieved from http://www.socialworkers.org/pubs/code/code.asp

National Association of Social Workers. (n.d.-b). History of social work research in mental health. Retrieved from http://www.socialworkers.org/research/nasw Research/0204mHealth/default.asp

National Long-Term Care Ombudsman Resource Center. (2009). About ombudsmen. Retrieved from http://www.ltcombudsman.org/about-ombudsmen

Rosenblatt, A., Samus, Q., Steele, C., Baker, A., Harper, M., Brandt, J., . . . Lyketsos, C. G. (2004). The Maryland assisted living study: Prevalence, recognition, and treatment of dementia and other psychiatric disorders in the assisted living population of Central Maryland. Journal of the American Geriatrics Society, 52, $1618-1625$.

Schonfeld, L. (2003). Behavior problems in assisted living facilities. Journal of Applied Gerontology, 22, 490-505.

Spitzer, W. J., Neuman, K., \& Holden, G. (2004). The coming of age for assisted living care: New options for senior housing and social work practice. Social Work in Health Care, 383, 21-45.

Steffens, D., Skoog, I., Norton, M., Hart, A., Tschanz, J., Plassman, B., . . . Breitner, J. C. S. (2000). Prevalence of depression and its treatment in an elderly population: The Cache County study. Archives of General Psychiatry, 57, 601-607.

U.S. Department of Health and Human Services. (2009). AoA fact sheet on the ombudsman program. Washington, DC: Author.

Utz, R. L. (2003). Assisted living: The philosophical challenges of everyday practice. Journal of Applied Gerontology, 22, 379-404.

Vinton, L. (2004). Perceptions of the need for social work in assisted living facilities. Journal of Social Work in Long-Term Care, 3(1), 85-100.

Watson, L., \& Lyketsos, C. (2006). Depression in assisted living is common and related to physical burden. American Journal of Geriatric Psychiatry, 14, 876-883.

Watson, L., \& Zimmerman, S. (2003). Depression in assisted living: Results from a four-state study. American Journal of Geriatric Psychiatry, 11, 534-542.

Williams, H. M. (2002). Social work skills in assisted living. Journal of Social Work in Long-Term Care, 1(3), 5-8.

Wilson, K. B. (2007). Historical evolution of assisted living in the United States, 1979 to the present. Gerontologist, 47(3), 8-22. 